\title{
Wykorzystanie metody TIG do regeneracji i naprawy form wtryskowych
}

\author{
The use of the TIG welding method \\ for the regeneration and repair of injection molds
}

\section{Streszczenie}

Omówiono regenerację form wtryskowych przy zastosowaniu procesów spawalniczych. Przedstawiono kryteria wyboru procesu. Zaprezentowano zastosowanie procesu TIG. Omówiono stosowane techniki naprawy form wtryskowych. Przedstawiono błędy mogące wystąpić podczas ich naprawy i regeneracji przy zastosowaniu procesów spawalniczych.

Słowa kluczowe: regeneracja, spawanie, napawanie, proces TIG

\section{Abstract}

Regeneration of injection molds by using welding processes is discussed in the above article. Criteria for the selection of the process are presented. The use of the TIG process is provided. Techniques used to repair injection molds are shown. Problems which may occur during their reparation and regenesration by using welding processes are discussed.

Keywords: regeneration, welding, hardfacing, the TIG welding process

\section{Wstęp}

W obecnych czasach przemysł przetwórstwa tworzyw sztucznych przeżywa trwający od początku XX wieku rozkwit. Wraz z rozwojem technologii, wprowadzania do produkcji coraz to nowszych, udoskonalonych metod wtrysku jak i używanych w tych procesach zróżnicowanych materiałów wzrosło również zapotrzebowanie na ilość przedsiębiorstw zajmujących się regenerowaniem i naprawianiem form wtryskowych. Ze względów ekonomicznych oczywiście ten odłam przemysłu jest złotym środkiem zarówno dla firm dokonujących regeneracji i naprawy, jak i firm które zlecają ten proces - taniej i oszczędniej jest oczywiście przedłużyć okres żywotności formy poprzez drobne korekty wprowadzane w razie potrzeb, niż konstruować nową formę od podstaw (chociaż nie zawsze jest to reguła) $[1 \div 3]$.

\section{Naprawa i regeneracja form przez napawanie}

W przemyśle przetwórstwa tworzyw sztuczny występują dwa główne procesy spawalnicze wykorzystywane do napraw form wtryskowych: TIG i spawanie laserem.

Niewielka część zakładów przemysłowych posiada urządzenia spawalnicze do napraw form wtryskowych. Większość zakładów zleca naprawę form wtryskowych w formie podwykonawstwa firmą zajmującym się wyłącznie naprawą lub regeneracją form poprzez spawanie. Wynika to z podejścia ekonomicznego i prowadzenia firm w ściśle wyspecjalizowanych branżach. W większości firmy te wyposażone są tylko w urządzenia spawalnicze do spawania metodą TIG, ale wraz z rozwojem coraz więcej z nich wyposażonych jest w urządzenia do spawania laserem. Te dwa procesy są naj- bardziej odpowiednie i najbardziej komplementarne do wykonania napraw form. W wyjątkowych sytuacjach niektóre firmy stosują również napawanie plazmowe.

\section{Wybór procesu napawania}

W celu wyboru procesu stosowanego do naprawy lub regeneracji form wtryskowych przeprowadzono porównanie na podstawie 10 kryteriów, uważanych za najważniejsze w odniesieniu do procesu naprawy i wpływu na eksploatację formy (tabl. I).

Tablica I. Kryteria wyboru procesu spawania do naprawy lub regeneracji form wtryskowych

Table I. Criteria for the selection of the welding process for reparation or regeneration of injection molds

\begin{tabular}{|c|c|c|c|c|}
\hline & Kryteria & TIG & PLASMA & LASER \\
\hline I & $\begin{array}{c}\text { Czas przeprowadzenia } \\
\text { procesu naprawy lub } \\
\text { regeneracji }\end{array}$ & שח & 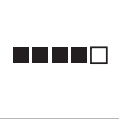 & 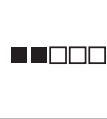 \\
\hline II & $\begin{array}{l}\text { Przenoszenie sprzętu } \\
\text { spawalniczego }\end{array}$ & שחשם & 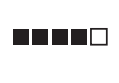 & 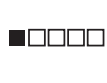 \\
\hline III & $\begin{array}{c}\text { Elastyczność w dostępie } \\
\text { do złożonego kształtu } \\
\text { geometrycznego }\end{array}$ & $\square=\square$ & घण口冋 & 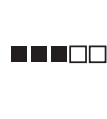 \\
\hline IV & $\begin{array}{c}\text { Elastyczność procesu } \\
\text { w wykonywaniu } \\
\text { spawania złożonych } \\
\text { kształtów }\end{array}$ & घणn日 & 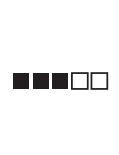 & 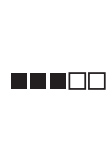 \\
\hline V & $\begin{array}{l}\text { Koszt za godzinę } \\
\text { użytkowania sprzętu }\end{array}$ & שםسص & 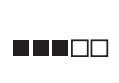 & घणमप \\
\hline
\end{tabular}

Dr hab. inż. Jacek Słania, prof. PCz; mgr inż. Łukasz Chłopczyński - Politechnika Częstochowska.

Autor korespondencyjny/Corresponding author. jacek.słania@is.gliwice.pl 


\begin{tabular}{|c|c|c|c|c|}
\hline VI & $\begin{array}{c}\text { Wygląd spoiny } \\
\text { i zgodność z materiałem } \\
\text { podstawowym }\end{array}$ & 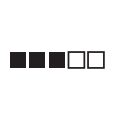 & $\mathbf{\square} \square \square \square$ & שח \\
\hline VII & $\begin{array}{l}\text { Metalurgiczna jakość } \\
\text { spawania i wpływ na } \\
\text { materiał bazowy }\end{array}$ & 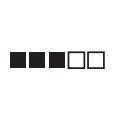 & $\mathbf{\square} \square \square \square$ & שחص \\
\hline VIII & $\begin{array}{l}\text { Miara niezawodności } \\
\text { i wykonalności procesu } \\
\text { (zależne od operatora) }\end{array}$ & 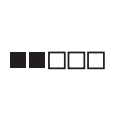 & $\square \square \square \square$ & שחص \\
\hline IX & $\begin{array}{c}\text { Konfiguracja urządzenia. } \\
\text { Czas potrzebny } \\
\text { do rozpoczęcia procesu } \\
\text { spawania }\end{array}$ & שᄆ & 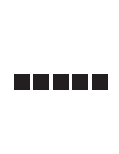 & 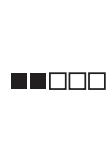 \\
\hline $\mathbf{X}$ & $\begin{array}{l}\text { Konieczność wstępnej } \\
\text { i / lub po procesowej } \\
\text { obróbki cieplnej }\end{array}$ & $\square \square \square \square \square$ & $\mathbf{\square} \square \square \square$ & 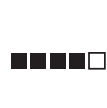 \\
\hline \multicolumn{5}{|c|}{ 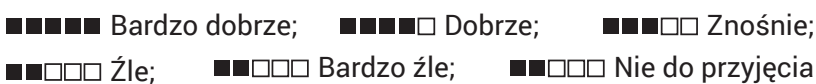 } \\
\hline
\end{tabular}

\section{Napawanie metodą TIG}

Łuk spawalniczy jarzący się między nietopliwą elektrodą, a materiałem spawanym topi powierzchnię materiału. W spawaniu TIG nie jest konieczne stosowanie materiału dodatkowego. Elementy spawane można łączyć przez przetopienie rowka spawalniczego. Jeżeli jednak stosowany jest materiał dodatkowy, jest on wprowadzany do jeziorka w sposób ręczny. Spoiwo zwykle jest dostępne w postaci pręta o długości $1 \mathrm{~m}$ i odpowiednio dobranej średnicy. Proces spawania TIG odbywa się w otoczeniu gazu ochronnego chemicznie obojętnego, najczęściej argonu lub mieszanki argonu i helu, wypływającego z dyszy uchwytu elektrodowego. Gaz osłonowy chroni jeziorko spawalnicze i elektrodę przed utlenieniem, ale nie ma wpływu na proces metalurgiczny. Spawanie metodą TIG charakteryzuje stabilność łuku elektrycznego, dzięki czemu jest to proces kontrolowany i dokładny.

Urządzenie do spawania metodą TIG jest przenośne i łatwe w obsłudze. Czas wymagany do rozpoczęcia procesu spawania (napawania), zależy tylko od rodzaju naprawy. Uchwyty spawalnicze występują w formie różnych ustawień geometrycznych elektrody (Rys. 1) co jest bardzo pomocne przy skomplikowanych elementach form wtryskowych lub miejscach trudno dostępnych (Rys. 2). Ponieważ jest to proces ręczny posiada dużą elastyczność, co umożliwia pracę w miejscach trudno dostępnych. Występują jednak uszkodze-

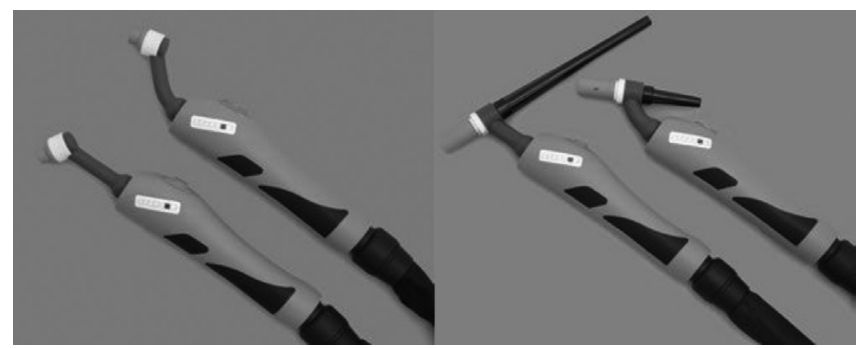

Rys. 1. Rodzaje uchwytów TIG

Fig. 1. Types of the TIG holders
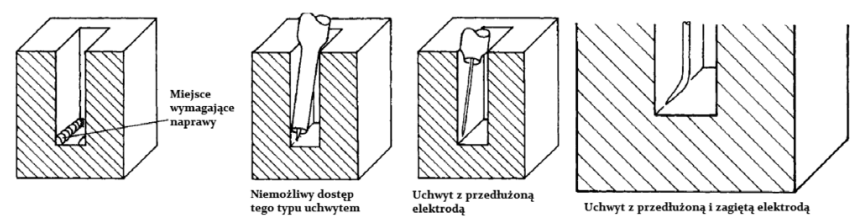

Rys. 2. Naprawa elementu formy wtryskowej w miejscu z utrudnionym dostępem

Fig. 2. Reparation of an injection mold component in a place of a difficult access nia do których dostęp może być niemożliwe. Wtedy elementy formy które muszą być naprawione są wykonywane na nowo zgodnie ze specyfikacją, lub wykonywane jest usunięcie fragmentu formy i odbudowywane w całości przez napawanie - w przypadku gdy są to niewielkie elementy (Rys. 3).

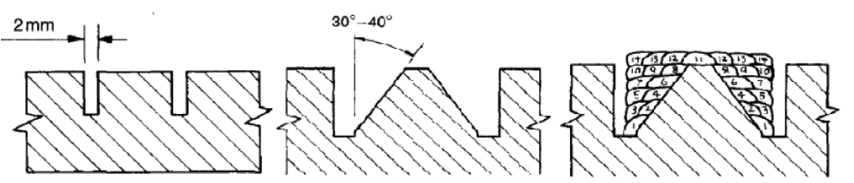

Rys. 3. Naprawa niedostępnego miejsca dla spawania procesem TIG Fig. 3. Reparation of an inaccessible place for the TIG welding process

\section{Wybór techniki naprawy formy wtryskowej}

Proces naprawy form wtryskowych rozpoczyna się od oceny stopnia zużycia formy wtryskowej, ustalenia zakresu regeneracji, wytypowania krawędzi, usterek, ubytków w formie a następnie uruchomienie prac regeneracyjnych.

Rozróżnić można cztery główne techniki naprawcze:

- Odbudowa powierzchni przez napawanie (rys. 4)

- Spawanie pękniętego elementu formy (rys. 5)

- Odbudowa krawędzi przez napawanie (rys. 6)

- Odbudowa elementów (rys. 7)

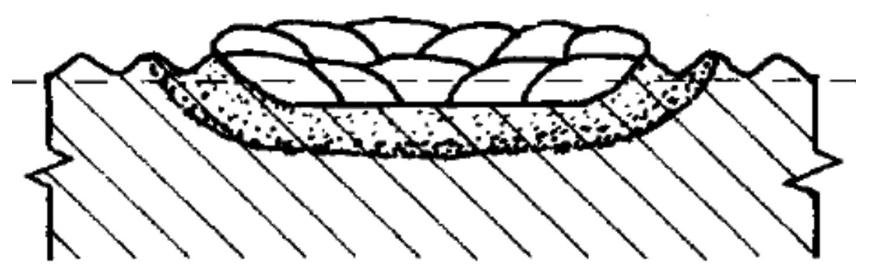

Rys. 4. Napawanie powierzchni

Fig. 4. Hard-facing of the surface

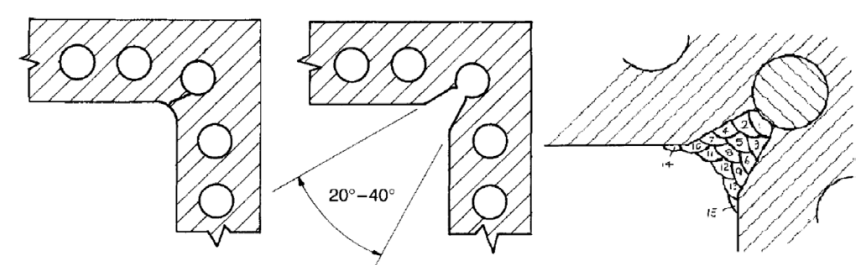

Rys. 5. Spawanie pękniętego elementu formy

Fig. 5. Welding of a cracked element of the mold

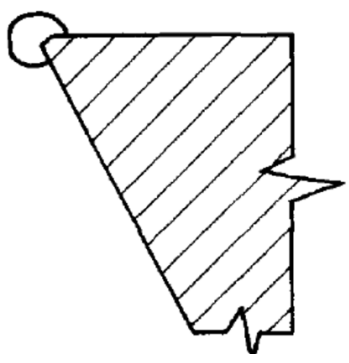

Rys. 6. Odbudowa krawędzi przez napawanie

Fig. 6. Rebuilding edges by hard facing

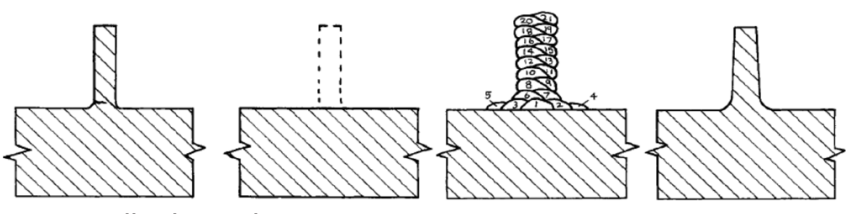

Rys. 7. Odbudowa elementów

Fig. 7. Rebuilding components

Dobór techniki naprawy zależy przeważnie od rodzaju naprawy do wykonania oraz w mniejszym stopniu od innych czynników, takich jak estetyka, koszty i ograniczenia geometryczne. Gdy naprawa jest wymagana we wnęce lub trudno dostępnym miejscu w formie wtryskowej możliwe jest podcięcie (wycięcie) elementu i odbudowa. 
Jeżeli ilość materiału potrzebna do odbudowy jest duża, preferowana jest również odbudowa elementu. Minimalizuje się w ten sposób wielkość naprężeń wprowadzonych podczas spawania (Rys. 7).

\section{Błędy popełniane podczas napraw i regeneracjach form wtryskowych}

Proces naprawy i regeneracji form wtryskowych należy do bardzo precyzyjnych procesów. Elementy regenerowane lub naprawiane należy odwzorowywać w sposób jak najbardziej zbliżony do oryginału lub specyfikacji. Wynika to z wpływu olbrzymich sił podczas procesu zamykania formy na wtryskarce. Elementy niewłaściwie wykonane mogą przyczynić się do wytworzenia produktu w procesie wtrysku o niesatysfakcjonujących właściwościach lub w najgorszym wypadku zniszczenia formy lub jej elementów, jeżeli jej elementy nie zostaną odpowiednio dopasowane.

Jednym z takich błędów w wykonaniu jest niewłaściwe zaplanowanie ilości i sekwencji wykonywania napoin. Podczas odbudowywania fragmentu formy wymagane jest nałożenie napoiny jako naddatek materiału w celu późniejszej obróbki materiału do wymaganego kształtu (rys. 8).
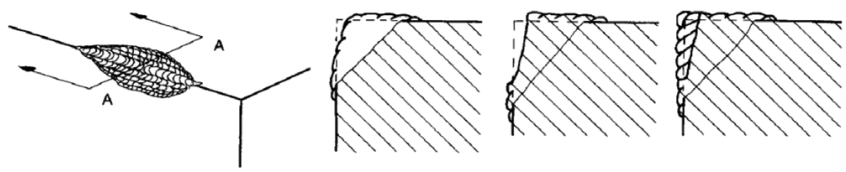

Rys. 8. Element odbudowywany bez naddatku materiału oraz etapy poprawy odbudowy

Fig. 8. Rebuilt element without a surplus of the material, and stages of an improvement of the reconstruction
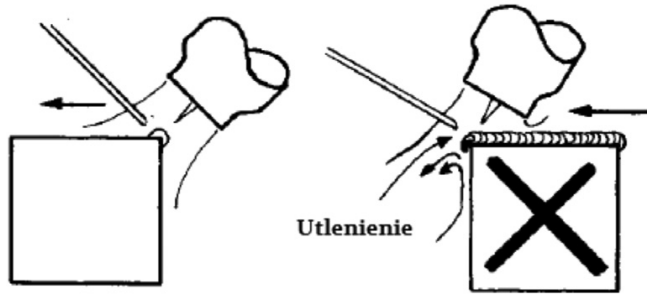

Rys. 9. Utlenienie spoiny przez niewłaściwy sposób jej układania Fig. 9. Oxidation of the weld by an improper way of its laying
Podczas pracy słabo wykwalifikowanych spawaczy często można dostrzec również niewłaściwy sposób ułożenia napoiny i jej utlenienie (rys. 9). W celu uniknięcia tego typu nieprawidłowości należy zaplanować wcześniej sposób nakładania napoiny eliminujący powstały defekt (rys. 10).

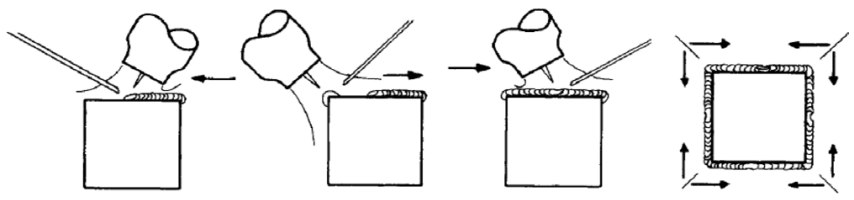

Rys. 10. Zaplanowany prawidłowy sposób kolejności ułożenia spoin Fig. 10. Planned proper way of an order of laying welds

Kolejną z wad występujących podczas procesu naprawy lub regeneracji form wtryskowych jest porowatość spoiny. Porowatość jest spowodowane przez pęcherzyki powietrza lub gazu uwięzionego $\mathrm{w}$ spoinie. Jedną z przyczyn porowatości jest niewłaściwie przygotowana powierzchnia (rys. 11). W celu uniknięcia tego typu niezgodności należy pamiętać o odpowiednim przygotowaniu powierzchni spawanej (rys. 12).

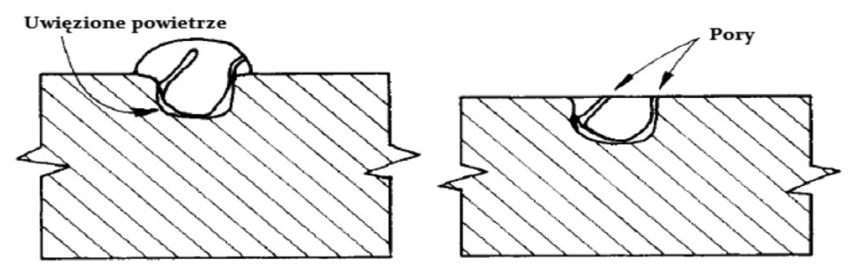

Rys. 11. Pory w spoinie spowodowane niewłaściwie przygotowaną powierzchnią

Fig. 11. Pores in the weld caused by an improperly prepared surface

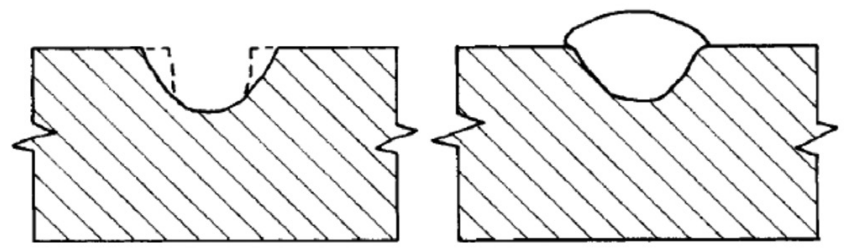

Rys. 12. Prawidłowe przygotowanie powierzchni spawanej - efekt spoina bez niezgodności

Fig. 12. Properly prepared welded surface - an effect - a weld without defects

\section{Podsumowanie}

Naprawa i regeneracja form jest bardzo ważnym elementem jej eksploatacji przez cały cykl jej wykorzystywania. Przedsiębiorcy wytwarzający produkt przy użyciu form wtryskowych muszą więc założyć proces regeneracji jako niezbędny w jej eksploatacji. W procesie naprawy i regeneracji należy położyć szczególny nacisk na wiedzę i szkolenia spawaczy. Wyeliminuje to potencjalne błędy podczas napraw, które generują dodatkowy koszty przez konieczność poprawy lub zniszczenia formy. Zastosowanie procesu napawania w procesie naprawy form, zmniejsza całkowity koszt eksploatacji w trakcie cyklu życia formy. Należy jednak pamiętać, że prawidłowe zaplanowanie przeglądów i regeneracji elementów na formach wtryskowych zapobiega zniszczeniom powstałym w trakcie eksploatacji.

\section{Literatura}

[1] Hollenbeck, J.; Micro welding: Applications beyond mold repair.; Mold Making Technology; październik 2001.

[2] Malkasian S. a al..; Micro-dimensional welding is putting some moldmakers ahead of their competition; Mold Making Technology; luty 2000.

[3] Thompson S.; Handbook of mold, tool and die repair welding; Abington Publishing; England; 1999.
[4] http://www.eltrex.net.pl/uchwyty-spawalnicze-tig,c24.html

[5] Bober M., Tobota K.: Badanie istotności wpływu podstawowych parametrów napawania plazmowego na geometrie napoin. Przegląd Spawalnictwa, vol. 87, nr 9, 2015, str. 24-28.

[6] Morel S.: Powłoki dla ochrony przed zużyciem elementów maszyn i urządzeń. Przegląd Spawalnictwa, vol. 87, nr 9, 2015, str. 65-69. 